\title{
The Art of Making Photos: Some Phenomenological Reflections
}

\author{
Thomas S. Eberle
}

Taking pictures with a digital camera or a mobile phone has become a widespread, ubiquitous activity. While some persons just take snapshots of particular scenes or events, it can be observed that many others also compose their photos to a certain degree by varying their position in different spatial directions, by using the zoom function and sometimes by giving advice to the friends they are photographing in regard to how they should pose. The common phrase of "taking pictures" suggests that the picture is already there and has just to be taken. The fact that each photo is the result of composing work to at least some degree is better captured if we speak of "making photos." This is even more relevant in the digital age where it has become common practice that layman photographers also edit their photos on the computer and increasingly on the camera and the mobile phone, too. The tools of the software programs that allow for editing pictures have become much simpler in recent years and more and more user-friendly. There are thus two processes of making photos: one of composing and photographing and a second of editing photos that have already been taken.

The goal of this chapter is - in line with Alfred Schutz - to reflect on the "doing" of making photos in a subjective perspective. I will focus on the first process only, the making of photos until the button of the camera is pressed. I attempt to describe some of my experiences and practices using phenomenological concepts. As I am a socialized human, my subjective perspective includes social and cultural influences of many sorts, shaped by my personal biography.

\footnotetext{
T.S. Eberle $(\bowtie)$

Institute of Sociology, University of St. Gallen, Tigerbergstrasse 2,

9000 St. Gallen, Switzerland

e-mail: thomas.eberle@unisg.ch
} 


\section{The Autobiographical Context}

Let me start with some information on my personal background: Photography has been my hobby for nearly all my life. I remember taking pictures already at the age of 9 or 10, with a simple camera but now and then guided by hints and tips of a semi-professional photographer, a friend of our family. My brother who was about 5 years older than me, continually motivated me by taking pictures himself, and he was the one who also advised me to strive for a SLR (mirror reflex)-camera "Pentax Spotmatic," the first camera that measured the light through the lens - a technical breakthrough at the time, in 1964, made in Japan. From then on I was well equipped and as the years passed by I made thousands of pictures, developing and editing my black and white photos in the darkroom myself. Later I used color-film, first diapositives (slides) and then color negative films. I changed cameras several times, buying each time an even more sophisticated model, and in 2001 I switched to digital photography, first with a compact, in 2004, also with a SLR camera. Over the years, however, the more I got involved in science as a profession, the less time I found for my hobby. It became a typical leisure time activity, something for holidays or for special occasions, like weddings or birthday parties of family members and close friends.

An interesting question to start with is why and how I do photography. The "why" is a psychological, not a phenomenological question. But the why is closely linked to the how, as I will show, and the how can be partly analyzed by means of phenomenological concepts. Since a close friend of mine who is an outspokenly anti-sportive and anti-touristic sociologist, asked me why the hell do I like travelling - something he just could not understand, neither emotionally nor rationally, as travelling was just a pure nuisance for him - since then I began to question myself. Suddenly an activity that I had always and undoubtedly enjoyed became questionable. This probing question rendered something problematic which so far had been a natural fact of my life, a natural routine, and it suddenly destroyed the innocence of my unquestioned activity. In a similar vein, I now began to reflect on my activity of making pictures. Why do I make photos at all? If you are eager to take good pictures, photography is work, and administering, selecting, and putting them together in albums or slide shows are even more work. Why engage in such work in leisure time?

That possessing a camera and making photographs are "good" practices was treated as an unquestioned truth in our family, but not so in the families of others, like my grandparents'. When my mother recently died I found nearly no photos of her childhood and youth. Her family owned only a very few photos taken by a professional photographer. It made me aware that in the 1920s and 1930s many families did not have a habit of making pictures themselves, and they did not have cameras of their own. The same was the case for my grandparents of both sides. By some unknown reason my father got a camera already as a boy and documented bicycle tours, hiking trips, and vacations, but not everyday life. So we have albums with photos of his parents, aunts and uncles, as well as some of his peers. And since 
the day he met my mother he also took many pictures of her. Since their encounter she became visually documented. Thus my personal motivation to make photos is deeply embedded in my family tradition - working as because motives - and it was regularly reinforced when my peers and classmates enjoyed the photos I took of them at parties, excursions, and other special occasions. It was generally agreed that I was the one who took the best photos, so I was "the" photographer in class.

Looking back on my life regarding my activities as a photographer, I remember the wonderful time when I was a scientific assistant with a modest salary that allowed me to survive and which gave me plenty of time to do whatever I liked to do. In those years I took a lot of photos and spent much time in the darkroom, where I could work quite creatively with the negatives at hand, experimenting with different kinds of photo papers, chemicals, expositions, focus, and frames. Taking photos was intimately linked to making photos. It was in every aspect a cheerful hobby. When, however, the obligations of a serious academic career got hold of me, it implied a farewell to those happy times. I ended up taking thousands of pictures at rare occasions - at vacations and special events - but I hardly found time to make something of all these pictures. I could have made albums and exhibitions or even have tried to find publishers for the best of my pictures, but I just left them in boxes and usually never went back to them, unless a friend or a family member persistently asked for some of them.

This made me aware, that I have lived only one part of the whole process for many years now: the part of taking pictures, but not the part of sorting them out, modifying them, putting them together in different thematic series, arranging them in an album, and so on. A rational choice would suggest that I soberly analyze the situation in a realistic manner and conclude: If I never look at the pictures, and if I don't pass them on to other people, why the hell am I still taking pictures? I could as well let it be. - Of course, there always remains the general hope that you will have all the time of the world once you are retired - and then you will look at all these pictures, at an age where you start to prefer looking back instead of looking forward. But all my friends and colleagues who have retired seem to be busier than ever. A realistic assessment probably suggests that all those photos will remain in those boxes forever, and it will be the task of my heirs to throw them away.

\section{Focusing on the Doing of Making Photos as an Activity in Its Own Right}

So why the hell do I continue to take photos? Why all that hassle running around in search of good pictures, if I finally end up not even looking at them? I started to reflect on my photographing during a vacation with my wife. Once more, I took thousands of pictures. In the past, my wife was often ambivalent about my photographing as the focus of my attention was not directed to her and our common experience and enjoyment of an event. Indeed, I can get caught by a kind of hunting 
drive and am not a normal human being anymore who socializes and interacts with others; instead, I find myself being on the prowl for good photos all by myself. Thus, my wife found herself often sitting alone much of the time when we were at parties. This was the downside for my wife. On the other hand, she also felt the enthusiasm and the excitement that I obviously displayed and this fascinated her, too.

Why this enthusiasm, where does it come from? The why has to do with the how. When contemplating on my doing photographing, I realized that there is a special attraction at work. I enjoy taking pictures even when I know that I possibly will never look at them again. I enjoy taking pictures as an activity in its own right. I try to capture the moment, the very moment in which I experience something remarkable - and so I photograph the blossoms of the cherry tree in our garden every year again. Not in order to produce a better photo than I made in the past years but in order to capture this very precious moment, this very unique experience.

A camera in my hand changes the mode of my perception: common-sensical everyday gazes are substituted by "photographic gazes" that focus on visual phenomena and are guided by the intention of taking "good" pictures. There is not "a" or "the" photographic gaze but there is a great variety of such gazes, focusing on different motives, themes, arrangements, perspectives, contexts, and so on. Gazes in search for photographs, however, have certain properties in common: They share a special "attention à la vie," are well aware of the noetic aspects of photographic phenomena, and have to come to terms with the givenness of their noema.

Taking pictures presupposes a photographic gaze, but also combines it with personal experience, technical expertise, and other kinds of practical knowledge. The photographer's intuition is coupled with more or less explicit, often highly routinized reflections on the choice of motives, their context and arrangement, proper perspectives, the degree of light as well as the interplay of light and shadow, the combination of different forms and shades of colors, the technical possibilities of the equipment at hand, and so on. Taking pictures also implies to press the button and this is an act in time. Let us look at this in more detail.

\section{The Photographic Gaze: A Special Cognitive Style?}

When I am on the hunt, I have a special gaze: I am scanning the surroundings for possible pictures. I call it "the photographic gaze," in analogy to John Urry's "touristic gaze." (Urry 2002) Friends report that they recognize immediately when I put on my photographic gaze - it can obviously be seen from my way of moving and looking around, I obviously make it "accountable" in an ethnomethodological sense. Subjectively, I experience this way of looking as a special cognitive style. The photographic gaze shifts my subjective system of relevances of everyday life and draws my attention to the beauty of a landscape or to an interesting scene of actors or to special moments of any sort that are worth of getting captured. My "attention à la vie" (Schutz 1967) is much more intense, and the tension of my consciousness is high and often extremely focused. Doing photography is an embodied action, but 
my senses are strongly reduced to the visual. Thus, participating in a party - to come back to the example I already mentioned - is a much more relaxed and multisensual, holistic experience then photographing the party. Many sorts of sensual and bodily experiences are just excluded from consciousness and my full attention is turned to the visual only. This way I experience a kind of époche. My doing photography has also a different form of sociality, my interaction with the people of a "natural" scene is - in contrast to photographing models, for instance - reduced to a minimum or even avoided totally in order to keep their behaviors "natural." In other words, I exclude myself from the community and take the role of a distant observer, watching the scene and trying to take pictures. My experience is mostly one of acting in solitude, being fully on my own and separate from the others. Even the time perspective is different as all my attention is directed to capturing the right moment, to making the perfect shot.

I definitely experience my photographic gaze as a different cognitive style. However, although the criteria that Schutz (1962a) developed to characterize multiple realities seem to be helpful for describing the subjective experience of doing photography, I am not in a different world in the sense of a "finite province of meaning." As a photographer, I am acting in the world of everyday life with the pragmatic attitude to make good pictures. My system of relevances directs my attention to the aesthetic side of my life-world, and with my pictures I contribute to the visibility of the beauty of this world. I also contribute to the aesthetic order when I focus on specific things that other people overlook or when I put things in a frame that fragments and orders the representation of my life-world. When experimenting or producing highly abstract photos of light and shadow, forms and colors, one recognizes that photography often involves a great deal of fantasy and fantasizing. But usually my photos do not belong to a world of fantasy but are representations of the everyday world, and my doing photography are pragmatic acts that bear the same accent of reality, too.

As I said, there is not only one photographic gaze, there are many such gazes. My brief sketch about photographing a party does not apply, for instance, to taking pictures of a model or to portrait photography. Here you interact with the photographed person, and making good photos depends very much on your social skills, on your ability to develop a warm, relaxed and easy-going working relationship with him or her. In addition, many other people may take snapshots at a party, not really worrying about the outcome and not really taking on a different cognitive style. My way of doing photography has a strong personal component.

\section{Composing Pictures}

With the photographic gaze I see everything in frames. Not only in natural and social frames in Goffman's (1974) sense but also in geometrical frames of a 4:3 proportion. Sometimes I would like to capture an exceptional "grand" experience, e.g., when standing in the forest or in a large urban space, but it is completely impossible to put 
the visual whole into a frame. There are embodied experiences of aesthetic orders that you simply cannot photograph. Even when using wide-angle or fish-eye lenses it would only distort what appears so magnificent. Beyond that, most scenes can be captured in frames, in a macro- or a micro-perspective.

Seeing the world in frames is certainly a constitutive but quite basic and only superficial part of the photographic gaze. Much more important is how you compose the picture. And an interesting question here is if you just take a snapshot from where you are sitting or standing or if you actively compose the picture. If you do so you will choose deliberately the fore- and background and their relation, a certain combination of light and shadow as well as of forms and colors and you are guided by some aesthetic criteria. You are then not just taking pictures, but making pictures, and the photographic gaze includes an aesthetic gaze.

Sometimes I take photos and sometimes I make photos. It is not an eitheror typology; the spectrum is fluid. I certainly do compose the photos, sometimes more, sometimes less carefully, and I do this quite intuitively, so there is also much experience and routine involved. There are three basic constitutive dimensions in which I compose: First, the spatial dimension. It has become a routine practice that I spontaneously see possibly "good pictures" and move around to arrive at a proper shooting position. I use stairways or chairs or kneel down, and sometimes I bend my back in such crazy ways to arrive at a proper shooting position, that I end up with pains in my back or even a lumbago. This spatial orientation is guided by my "aesthetic eye," by my ideas of what makes a "good picture."

A second constitutive dimension is time, especially timing. A photographer lives in his durée, in his inner time (Schutz 1967), and he is well aware that a photograph freezes an instant of a phenomenon or an event, captured in a tiny fraction of a second. If the photographed object is static in time, the instant of taking the picture is not of great importance - you then may want to choose the right time of the day where the interplay of light and shadow is optimized. What Claude Monet showed with his picture series of the cathedral of Rouen, produced in the years 1892-1894, applies also to photography of course. If the object is moving, or even moving fast, the crucial task of a photographer is capturing the "right moment." For example, when taking a photo of a "natural" scene of interacting people, you wish to avoid that persons have closed eyes or strange faces or that they make a gesture which covers their face or the face of others, or that somebody steps in between your camera and the targeted object right before you push the button, and so on. A good photographer has to be able to "tune in" with the natural and social rhythms of the phenomena that he intends to photograph. In contrast to the "tuning in" in a musical relationship (Schutz 1964), he does not have to hit the right tone. But he certainly needs to "tune in" with a developing sequence in order to choose the right moment for making the photo. In other words, he must be aware of the sequence of events, behaviors, and actions and their rhythm, their temporal development, and must base his actions on his retentions of the fading presence as well as on the protentions of what comes next. In Schutz's (1967) analysis, the retentions are filled while the protentions are empty - they contain the "that" and not the "what." But this is only partly the case. A photographer must anticipate what is going to happen 
next, and coordinate his own acting with what he observes and what he anticipates to happen in the next few seconds. "Anticipate" is a word that is a little too strong here - Schutz says that anticipating is a reflective act, and I do not mean a reflective act here - protentions are rather experienced as a kind of "feeling" or a "sense" of what's next. In this respect protentions must at least hypothetically be "filled," based on experiences of how a given sequence of an event or course of action will "typically" develop.

A third constitutive dimension is the social. Insofar as I referred to social events and human behaviors, I implied the social dimension already when analyzing the temporal one, and also in some paragraphs before that. An additional point is this: Although my making photos is very intuitive and quite spontaneous, I act along aesthetic criteria that are socially derived, that are of cultural origin, and that are embedded in my routines. The interesting thing is that I have some difficulties to spell these criteria out. I have to do self-observation in action, or I have to look at my pictures and engage in a constitutional analysis, guided by Husserl's technique of free variation, as Schutz (1962b) described it in his Essay "Some Leading Concepts of Phenomenology." Basic principles are detected if one considers why one deletes pictures: Because they are blurred, too bright, or too dark; because the intended object is not any more or only partly in the picture; because the person or the animal has turned its back to you (which usually is not very interesting); because something or somebody got between you and your objects right when pressing the button; and many more.

However, as the world of photography is populated by many creative people, all existing aesthetic criteria are also challenged. Not even the principle of the "golden cut" (or the "golden means") is undisputed anymore, although many professional photographers were praised for that mode of composition. Nowadays it has become a common practice in many fields of (post-) modern society to break the rules. There exists now a rather complex multiplicity of different photographic styles, and a lot of experimenting with different modes and new styles is going on. Examining my personal aesthetic criteria is, then, nothing more than a reflection on my subjective stock of knowledge at hand, on the conscious and unconscious criteria I am applying when making photos. Comparing these with the multiplicity of other criteria that are used in photography reveals how specific my own criteria are, opening up new horizons and potential for personal change.

\section{Technical Aspects}

Composing pictures is strongly intertwined with handling the technical features of the camera. If you know how your camera works you can use some of its functions, deliberately strive for certain effects, and anticipate the results. The technical progress during the past decade has been enormous - most of my former skills as a "good" photographer have become irrelevant: The framing, the focusing, the right exposure, partly even the timing of the shot, the processing of film negatives 
and paper positives in the darkroom, and so on. And more and more have been automatized, especially focusing and exposure, two crucial practices that formerly were quite challenging and that only a few people really managed well. Nowadays, people can take pictures with their automatic digital camera, make many shots in a series and thus ensuring they got the "right" moment, and even choose the frame later by editing the picture on the computer. Thus, many people make good photos nowadays just by pressing the button very often and varying the frame. And most of them do not even choose the predefined programs, e.g., for landscapes, portraits, nighttime, fast-moving objects, etc., which involve different constellations of aperture and time, but use their camera permanently in the same position: automatic.

In contrast, a professional photographer will still use his or her knowledge about the physics of light, the effect of different lenses, and the workings of the built-in electronics. Composing pictures is then intimately tied to the knowledge and the skills with which one handles one's camera. Due to the success of automatizing digital cameras, it has nowadays, however, become much more difficult to produce significantly better pictures than laypersons. Is making "good photos" still an art? Or is it an art only if the photos themselves are considered as art?

\section{Photography as Art}

Physical and technical knowledge and camera handling skills are only means but do not guarantee "good" pictures. Photos freeze a certain moment in time. Great photos tell a story, they display a great density, and they capture something that is considered as "typical" of an era or a social milieu. When are photos considered as art? This is not a phenomenological, but a sociological question and can be researched empirically. In any case, there has been a long discussion during the past decades if photography can be art at all, and recently it has been extended to the question if videos can be art. Many photographers considered themselves as artists but most of them had to make a living as photojournalists selling their photos to publishers. The American photographer Eugene Smith (1918-1978) is a good example of how much tension between the systems of relevances of an artist in contrast to that of a journal publisher can arise. After quarrelling with the editors of Life Magazine over their restrictive treatment of his photo series, he left in anger and joined Magnum, the famous cooperative agency founded by Robert Capa, Henri Cartier-Bresson, and others. By Magnum he was commissioned to produce a de luxe bicentennial volume of texts and pictures on Pittsburgh to be completed in a few weeks. Instead of delivering about a 100 pictures for a chapter of the book, he made tens of thousands photos and it took him 4 years due to his perfectionist professional attitude. "What kept him there off and on ... was a fierce desire to break free of all external editorial constraints, to develop an alternative way of working as 
an independent 'photo historian or journalist', and to produce an 'essay' true to his imperious vision." (Trachtenberg 1998, p. 174) He wanted to create a personal photographic essay, a goal he has never reached. He would just not deliver a less than perfect photo.

Nowadays, Smith is considered an artist, although he worked as a photo reporter. Besides Pittsburgh he did other great reportages, for instance, of a Spanish village, A Man of Mercy (which was Albert Schweitzer), or Minamata, the industrial waste scandal, and other great coverages (Smith 1998). Although he was a photojournalist, "Smith was to labor constantly to give his photographs the timeless quality that he admired so much in the [paintings of the - T.S.E.] Old Masters, which would free him from chance everyday events - though he still used them to advantage when necessary." (Mora 1998, p. 16) Painting has the power "to perpetuate an idea, using the symbolic overtones and strong aesthetic presence that can come from being able to construct the whole image." (ibid) "Photography however is handicapped by a limited time-scale, linked as it is to particular events and news." (ibid.) "Photojournalism inevitably loses its impact along with the events it records (its durability is limited to the 'factual impact' of photography), and Smith attempted to buy time with his pictorial allusions, creating images whose aesthetic relevance would override their factual one." (ibid.) In his own words, Smith says: "I have not been content to remain merely a 'seeing photographer' ... I believe ... that finally, though I be intimately truthful of an individual moment, I must be ... of symbolization of the universal ...." (ibid.) To fulfill this intention, "Smith embraced extreme manipulation without reserve." (ibid.) He carefully prepared the stage and arranged scenes, he hired trucks and herds of cattle and engaged the inhabitants of a village as supernumeraries, and he did castings in order to find appropriate proponents. Smith even comments on his war assignments: "Some say that [since] I am being forced to shoot on the fly the results will be truer. But this is false... One must observe and feel the surroundings and interpret them, translating them into finished work." (Hill 1998, p. 338) And the logical conclusion is: "That which escaped his control in front of the camera must be brought to account after the fact, mainly by painstaking printing techniques." (ibid.) Smith modified the pictures in the dark room as we do it on the computer today.

When doing a reportage, you try to capture "typical" scenes. Of course, composing a picture can swiftly extend to arranging a picture. The line between fact and fiction is fluid even in documentary photography. The history of documentary photography is full of arranged scenes. Even pictures that became famous global icons were later revealed as either reconstructions or fakes. Nevertheless, they documented something "typical," and many found their way into exhibitions at art galleries and photo museums because they are "great" pictures. It is difficult for a photographer to be in the right place at the right time when something happens, it is therefore tempting to arrange scenes you would like to capture. It is well known that even war photos were often arranged. 


\section{Conclusion}

For myself, I hardly arrange pictures except when making group pictures of persons. I attempt to capture "natural" scenes and events that happen in my life-world anyway. I do not arrange but I do certainly compose my photos (more or less). Some phenomenological concepts proved helpful in analyzing this activity. When comparing my photos with certain (not so good) pictures that are exhibited at art museums, I sometimes ask myself: What makes these photos pieces of art? Maybe I also produce some photos that might be considered as art but I do not care. My main activity is making photos in the very moment things happen, and I consider doing photography as an activity in its own right. I enjoy making photos as it makes me look at things wide-awake and with great intensity: I see much more than many other people, I look at things more carefully and accurately, and it makes my life thereby richer. I can remember many things and events much better because I perceived them with my intense photographic gaze. Thus, making photos gives my life much more intensity, richness, beauty, and joy. It is an activity worth of doing in its own right.

\section{References}

Goffman, E. 1974. Frame analysis. New York: Harper Colophon.

Hill, J.T. 1998. W. Eugene Smith: His techniques and process. In W. E. Smith. The camera as conscience, ed. G. Mora and J.T. Hill. London: Thames and Hudson.

Mora, G. 1998. W. Eugene Smith: The arrogant martyr. In W. E. Smith. The camera as conscience, ed. G. Mora and J.T. Hill, 6-27. London: Thames and Hudson.

Schutz, A. 1962a. On multiple realities. In Collected papers Vol. I: The problem of social reality, ed. A. Schutz, 207-259. The Hague: Martinus Nijhoff.

Schutz, A. 1962b. Some leading concepts of phenomenology. In Collected papers Vol. I: The problem of social reality, ed. A. Schutz, 99-117. The Hague: Martinus Nijhoff.

Schutz, A. 1964. Making music together: A study in social relationship. In Collected Papers Vol. II: Studies in social theory, ed. A. Schutz, 159-178. The Hague: Martinus Nijhoff.

Schutz, A. 1967. The phenomenology of the social world. Evanston: Northwestern University Press.

Smith, W.E. 1998. In The camera as conscience, ed G. Mora and J.T Hill. London: Thames and Hudson.

Trachtenberg, A. 1998. W. Eugene Smith's Pittsburgh: Rumours of a city. In W. E. Smith. The camera as conscience, ed. G. Mora and J.T. Hill, 174-182. London: Thames and Hudson.

Urry, John. 2002. The tourist gaze, 2nd ed. London: Sage. 
Michael Barber • Jochen Dreher Editors

\section{The Interrelation of Phenomenology, Social Sciences and the Arts}

黑 Springer 


\section{Editors}

Michael Barber

Philosophy

St. Louis University

St. Louis, USA
Jochen Dreher

Social Science Archive

University of Konstanz

Konstanz, Germany
ISSN 0923-9545

ISBN 978-3-319-01389-3

DOI 10.1007/978-3-319-01390-9

Springer Cham Heidelberg New York Dordrecht London

Library of Congress Control Number: 2013946715

(C) Springer International Publishing Switzerland 2014

This work is subject to copyright. All rights are reserved by the Publisher, whether the whole or part of the material is concerned, specifically the rights of translation, reprinting, reuse of illustrations, recitation, broadcasting, reproduction on microfilms or in any other physical way, and transmission or information storage and retrieval, electronic adaptation, computer software, or by similar or dissimilar methodology now known or hereafter developed. Exempted from this legal reservation are brief excerpts in connection with reviews or scholarly analysis or material supplied specifically for the purpose of being entered and executed on a computer system, for exclusive use by the purchaser of the work. Duplication of this publication or parts thereof is permitted only under the provisions of the Copyright Law of the Publisher's location, in its current version, and permission for use must always be obtained from Springer. Permissions for use may be obtained through RightsLink at the Copyright Clearance Center. Violations are liable to prosecution under the respective Copyright Law.

The use of general descriptive names, registered names, trademarks, service marks, etc. in this publication does not imply, even in the absence of a specific statement, that such names are exempt from the relevant protective laws and regulations and therefore free for general use.

While the advice and information in this book are believed to be true and accurate at the date of publication, neither the authors nor the editors nor the publisher can accept any legal responsibility for any errors or omissions that may be made. The publisher makes no warranty, express or implied, with respect to the material contained herein.

Printed on acid-free paper

Springer is part of Springer Science+Business Media (www.springer.com) 


\section{Contents}

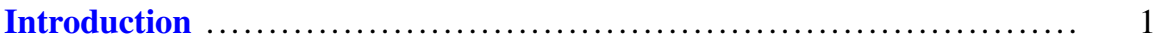

Michael Barber and Jochen Dreher

Part I Aesthetics and the Social Sciences

Irrelevant Spheres and Vacancies of Artworks:

Phenomenological Aesthetics Revisited ............................ 11

Masato Kimura

Cultural Science in Literary Light $\ldots \ldots \ldots \ldots \ldots \ldots \ldots \ldots \ldots \ldots \ldots \ldots, 21$

Lester Embree

Projection, Imagination, and Novelty: Towards a Theory

of Creative Action Based on Schutz .............................. 31

Hubert Knoblauch

Imagination and the Social Sciences .............................. 51

Hisashi Nasu

Functional Purposelessness: The "Practical Meaning" of Aesthetics ..... 69

Hans-Georg Soeffner

Art as a Paradoxical Form of Communication ........................ 83

Ilja Srubar

When Sociology Meets the Work of Art: Analytical

Frameworks to Study Artistic Production and Reception................ 95

Anna Lisa Tota

\section{Part II Literature}

Crossing the Finite Provinces of Meaning: Experience and Metaphorizing of Literature and Arts

Gerd Sebald 
Sancho Panza and Don Quixote: The Documentary and the Phenomenological Methods of Analyzing Works of Art

Amalia Barboza

Literature as Societal Therapy: Appresentation, Epoché, and Beloved .... 143 Michael Barber

The Man Without Qualities and the Problem of Multiple

Realities: Alfred Schutz and Robert Musil Revisited

Martin Endress

Entangled into Histories or the Narrative Grounds of Multiple

Realities

Annette Hilt

"The Universe that Others Call the Library": Reconstructing the Symbolic Mystifications of the World of Everyday Life

Jochen Dreher

Part III Music

The Tuning-in Relationship: From a Social Theory of Music

Towards a Philosophical Understanding of Intersubjectivity

Carlos Belvedere

Mutual Tuning-In Relationships and Phenomenological Psychology

Chung-Chi Yu

Music, Meaning, and Sociality: From the Standpoint of a Social

Phenomenologist

Andreas Goettlich

Artistic Practice, Methodology, and Subjectivity: The "I Can"

as Practical Possibility and Original Consciousness

Andreas Georg Stascheit

Musical Foundation of Interaction: Music as Intermediary Medium.

Mototaka Mori

\section{Part IV Film and Photography}

Interpreting Film: The Case of Casablanca

George Psathas

A Phenomenological Inquiry of Rashomon

Ken'ichi Kawano 